\title{
Management competencies required in the transition from a technician to a supervisor
}

\begin{tabular}{|c|c|}
\hline \multicolumn{2}{|c|}{$\begin{array}{l}\text { Authors: } \\
\text { Sibongile R. Mahlangu } \\
\text { (Kubheka) }^{1} \\
\text { Cookie Govender }^{1}\end{array}$} \\
\hline \multicolumn{2}{|c|}{$\begin{array}{l}\text { Affiliations: } \\
{ }^{1} \text { Department of Industrial } \\
\text { Psychology and People } \\
\text { Management, University of } \\
\text { Johannesburg, South Africa }\end{array}$} \\
\hline \multicolumn{2}{|c|}{$\begin{array}{l}\text { Correspondence to: } \\
\text { Sibongile Mahlangu } \\
\text { (Kubheka) }\end{array}$} \\
\hline \multicolumn{2}{|c|}{$\begin{array}{l}\text { Email: } \\
\text { Sibongile.kubheka@eskom. } \\
\text { co.za }\end{array}$} \\
\hline \multicolumn{2}{|c|}{$\begin{array}{l}\text { Postal address: } \\
\text { PO Box 401, Midstream } \\
\text { Estate 1692, South Africa }\end{array}$} \\
\hline \multicolumn{2}{|c|}{$\begin{array}{l}\text { Dates: } \\
\text { Received: } 05 \text { May } 2014 \\
\text { Accepted: } 10 \text { Feb. } 2015 \\
\text { Published: } 18 \text { May } 2015\end{array}$} \\
\hline \multicolumn{2}{|c|}{$\begin{array}{l}\text { How to cite this article: } \\
\text { Mahlangu (Kubheka), S.R., } \\
\text { \& Govender, C. (2015). } \\
\text { Management competencies } \\
\text { required in the transition } \\
\text { from a technician to a } \\
\text { supervisor. SA Journal } \\
\text { of Human Resource } \\
\text { Management/SA Tydskrif vir } \\
\text { Menslikehulpbronbestuur, } \\
\text { 13(1), Art. \#644, } 8 \text { pages. } \\
\text { http://dx.doi.org/10.4102/ } \\
\text { sajhrm.v13i1.644 }\end{array}$} \\
\hline \multicolumn{2}{|c|}{$\begin{array}{l}\text { Copyright: } \\
\text { C 2015. The Authors. } \\
\text { Licensee: AOSIS } \\
\text { OpenJournals. This work is } \\
\text { licensed under the Creative } \\
\text { Commons Attribution } \\
\text { License. }\end{array}$} \\
\hline \multicolumn{2}{|l|}{ Read online: } \\
\hline 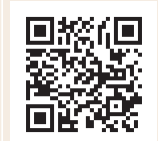 & $\begin{array}{l}\text { Scan this QR } \\
\text { code with your } \\
\text { smart phone or } \\
\text { mobile device } \\
\text { to read online. }\end{array}$ \\
\hline
\end{tabular}

Orientation: Technicians are frequently promoted to supervisory positions based on their technical abilities, with scant attention focused on developing management competencies. This oversight often poses significant challenges. The effective transition from technician to supervisor is important in any organisation.

Research objective: The primary objective is to identify and verify the competencies that are required for a technician and a supervisory position; the secondary objective is to identify the gap that must be filled with relevant training interventions to enable technicians to make an effective transition to a supervisory position.

Motivation for this study: The identification of the management competencies required for a technician who makes a career change to a supervisor position.

Research method: The sequential mixed method approach was used to enable the twophase data collection process: phase one was the quantitative phase and phase two was the qualitative phase.

Main findings: The overall findings confirm that there are indeed management competencies that technicians require training and development on before being promoted to a supervisory position.

Implication: Organisations need to identify the key competencies for a technician and a supervisor and implement development or training interventions that are essential to successfully transition an employee from the level of a technician to the level of a supervisor.

Contribution: Organisations need to implement essential development or training interventions focused on developing management competencies and put in place support interventions such as coaching, job shadowing, mentoring and networking.

\section{Introduction}

For organisations to achieve a competitive advantage over their competitors, they need to build on the skills and knowledge of their current employees (Gratton, 2000; Ito \& Brotheridge, 2005). Organisations need to create a pool of skilled, competent technicians and supervisors who are able to deliver on required and projected products and services (Mahapatro, 2010). The identification of the competencies that are required for a technician and for a supervisor is of importance to any organisation. According to Woodruffe (2003), competencies are fundamental distinguishable characteristics that an individual uses to perform a specific job or output successfully.

A notable challenge that contemporary organisations face is the management function of transitioning a technician from a subject matter expert to a supervisor (Badawy, 1995; Barley, 1996; Hood, 1990). The challenge often is occasioned by the role differences; a technician largely uses hands-on experience and logical reasoning competencies, whilst a supervisor requires management, leading, planning, directing, and people skills (Hilgert \& Leonard, 2008; Hodgetts, 2007; Mintzberg, 2009; Rue \& Byars, 2004).

Unfortunately, most technicians lack the required management competencies that are required for a supervisory position. Therefore, the skills differences that exist between a technician and a supervisor are not being addressed in the workplace. In view of these findings, it seems important to identify, verify and make recommendations on the development of management competencies that are required when transitioning technicians to supervisory positions. 


\section{Trends from the literature Key competencies essential for a technician}

According to the Engineering Council of South Africa (ECSA, 2003), technical competencies refer to the knowledge, skills and techniques that are required to effectively operate, test, inspect, construct, install, repair and maintain relevant allocated work areas as per the prescribed standards, legislations, regulation guidelines and code of practice. Technical competencies are the knowledge, skills and behaviours that are required to perform a specific task (Reio \& Sutton, 2006). Technical competencies focus on the application of relevant technical knowledge and skills as per the predefined standards and guidelines in order to effectively perform the required tasks (Becker, 2009; Technician Council, 2011; United States Office of Performance Management, 1999).

Review of the Analyzer Technician Competency Model (Analyzer Technician Opportunities Project, 2009) and the United States Office of Performance Management (1999) provides six competency themes that are critical for the technician position. These competency themes can be grouped as follows:

- Theme 1: Maintenance, operation, transmission and distribution of activities per allocated area.

- Theme 2: Technical operations, principles, functionality and techniques.

- Theme 3: Investigation, inspection and modification of allocated systems.

- Theme 4: Quality control.

- Theme 5: Safety knowledge and compliance.

- Theme 6: People skills.

Each of the competency themes was further broken down into actual activities. In addition to the identified themes and actual activities, the National Academy of Engineering (2005) states the importance of sub-competencies, which are mathematics, technical qualifications and experience in the technical field. These sub-competencies are required in the technical field. Theoretical analysis of the technical documents and the energy utility industry's job profiles of the technicians indicates that matric (Grade 12), 2 years' technical experience and mathematics at NQF Level 4 are sub-competencies that are required for a technician position.

\section{Key competencies essential for a supervisor}

Greer and Plunkett (2000) state that a supervisor's role includes providing subordinates with instructions and relevant training to enable them to perform their roles effectively. A supervisor is a person who has the discretion and authority to coordinate, direct, and oversee daily work activities of individuals and teams. Supervisors need to ensure that the teams' operational plans are formulated and monitored (De Beer \& Rossouw, 2005); therefore, central to management or supervising others are the four functions of management, namely planning, organising, leading and
TABLE 1: Mechanisms for easing the transition to management.

\begin{tabular}{ll}
\hline Number & Mechanisms \\
\hline 1 & Identify managerial potential \\
2 & Employ better selection methods \\
3 & Make the dual ladder work \\
4 & Provide appropriate support, orientation and coaching \\
6 & Reward managers for subordinates' development \\
7 & Provide training in the functions and skills of management \\
\hline Source: Adapted from Badawy, M. (1995). Developing managerial skills in engineers and
\end{tabular}
scientists: Succeeding as a technical manager. (2nd edn.). New York, NY: John Wiley \& Sons

controlling, and the five skills in addition to technical skills, namely dealing with people, information-sharing, decisionmaking and problem-solving (De Beer \& Rossouw, 2005; Hilgert \& Leonard, 2008; Hood, 1990; Howard, 2003; Mintzberg, 2009; Rue \& Byars, 2004; Seethamraju \& Agrawal, 1999; Yulk, 2008).

In addition, the literature review and the theoretical analysis of the technical documents and the industry-wide job profiles of the energy utility industries provide additional skills that are required for a supervisory position. Those skills include interpersonal relations, leadership behaviour, administration, budgeting and knowledge of human resources (HR) processes and systems.

\section{Transition from a position of technician to supervisor}

Transition refers to a career progression from one lowerlevel position to another higher-level position, a shift from the technical workforce to the managerial role to increase economic and professional standing (Ebberwein, Krieshok, Ulven \& Prosser, 2004; Louis, 1980; Osipow \& Fitzgerald, 1996; Roberts \& Biddle, 1994). Hall (2002) and Howard (2003) argue that transition is a process of changing jobs or professions.

The transition from a technician position to a supervisory position needs to be managed. Many companies often make the mistake of selecting the best-performing technical employee for promotion to a supervisory or management level without providing them with any supervisory or managerial training, believing that they will make good supervisors or managers (Badawy, 1995; Lewis, 2009; Roberts \& Biddle, 1994; Thamhain, 1991). Transition should not be a single event, but should occur over a period of time (Badawy, 1995; Handschin, 2007; Newstrom, 2007). According to Charan, Drotter and Noel (2001), transition from a technician to a supervisor involves recognising the required competencies essential for effectiveness at different performance levels. Badawy (1995, p. 54) identifies the seven mechanisms for easing the transition to management, as shown in Table 1.

\section{Challenges organisations face in transitioning a technician a supervisor}

Handschin (2007) evaluates the challenges of promoting a technician to supervise or manage a department. According to Handschin, the nature of the challenges that 
organisations often face with technicians who are promoted to a supervisory position is the fear of disengaging from the technical field. Technicians are confident in working with tools and equipment and therefore they often find it difficult to delegate these tasks to their teams. They may remain fixed in their specialist positions as technical experts (Badawy, 1995; Ebberwein et al., 2004; Hood, 1990; Kadushin \& Harkness, 2002).

This is supported by Charan et al. (2001) who argue that organisations need to put in place mechanisms to deal with the vague sense of letting go of the current role and adding on the new role. This transition stage needs to be handled swiftly and efficiently to avoid slips, unnecessary stress, low morale and substandard performance (Hood, 1990; Howard, 2003).

Katz (2003) argues that interpersonal skills, which include open communication and trust-building, are critical for a technician who makes a transition to a supervisory position in order to delegate work effectively and to interact with teams in an open and transparent manner. The transition stage, if not handled correctly, may result in stressful effects for the new supervisor in trying to execute the job effectively (Aucoin, 2002; Badawy, 1995; Freedman, 1998; Handschin, 2007; Hood, 1990; Kadushin \& Harkness, 2002).

\section{Method}

A sequential mixed method approach was used. The rationale for using both the quantitative and qualitative approaches was to ensure reliability and validity of research results (Bernardi, Kleim \& Von der Lippe, 2007; Creswell \& Plano, 2011). Jogulu and Pansiri (2011) argue that the use of qualitative and qualitative approaches is useful in ascertaining the epistemological coherence of data gathered. The researchers found that the topic was not well researched, there was limited data available on the subject, rich data was needed and therefore the sequential mixed method approach was appropriate.

The quantitative approach was applied first to identify the competencies required for a technician and a supervisor and the qualitative approach was applied later to validate the list of competencies, assign a degree of importance and recommend any further development or training interventions that are essential to successfully transition an employee from the level of a technician to the level of a supervisor.

The research approach was applied as depicted in the Figure 1.

\section{Phase 1: Quantitative approach}

Quantitative research is defined as a research methodology that focuses on the discovery of an in-depth, deeper meaning (Rubin \& Babbie, 2005). According to Teddlie and Tashakkori (2009), quantitative research refers to the interpretation of

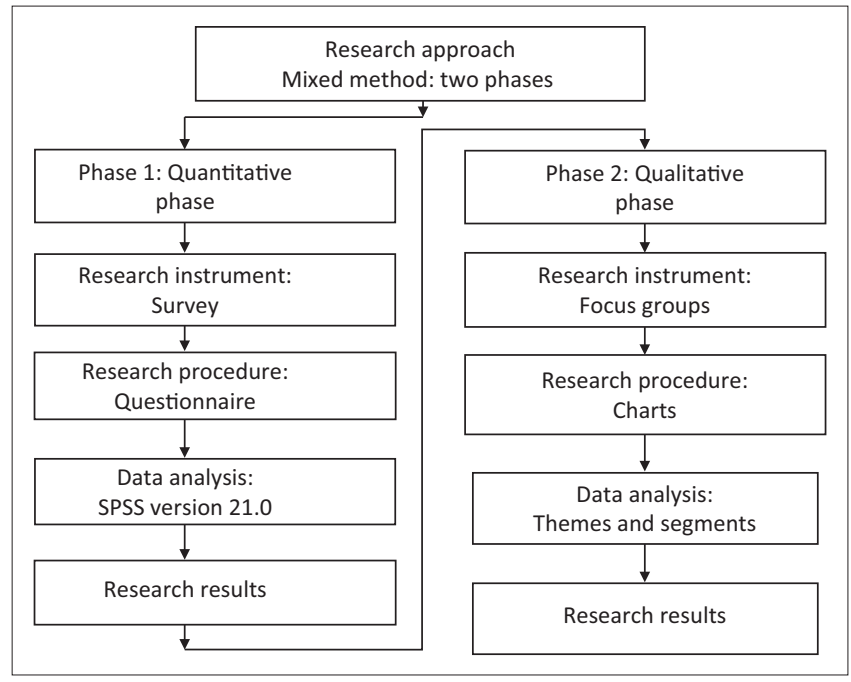

Source: Prepared by researchers (2012)

FIGURE 1: Research approach.

data to obtain numerical results. It enables the researchers to employ numerical assessment and analysis of data to the research questions (Zikmund, Babin, Carr \& Griffin, 2013). The quantitative phase was executed to identify the competencies required for a technician position and a supervisor position. In the quantitative phase, a survey was developed, based on the data gathered during the literature review.

\section{Sample size}

A sample size of 250 participants was randomly selected from (with acquired management approval) the population of Eskom technicians, supervisors and HR administrators from the Mpumalanga, Gauteng and Limpopo provinces who had a majority of technicians who were promoted to the supervisory position. The HR administrators were invited to participate in this study because they play a supporting role in advising the technicians and supervisors regarding HR-related enquiries.

\section{Ethical considerations}

Confidentiality was maintained throughout this study, as all participants were anonymous during data-capturing. The purpose of this study was clearly communicated to all participants prior to their engagement in this study. Permission to conduct the study, to utilise the organisation job profiles as the basis for the study and to publish the results with the organisation acknowledged was granted by Eskom management. Information on the time allowed for the completion of the questionnaire and instructions on how to complete the questionnaire wwere communicated to all participants. Furthermore, participants were informed that their participation in this study was voluntary, that all data gathered will be used for research purposes only and that the results of this study will be made available upon request.

\section{Research instrument}

A questionnaire was constructed by the researchers using the data gathered in the literature review. The questionnaire 
focuses on three specific parts: the first part focuses on biographical data, which addresses information on job title, division, department, age profile, gender profile, highest qualification, experience in the technical field and experience in the supervisory field. The questionnaire was structured in a closed-ended rank order scale.

The second part of the questionnaire focuses on technician competencies and addresses the maintenance, technical operation, investigation, inspection and modification of allocated systems, quality control, safety knowledge and mathematics, whilst the third part focuses on supervisory competencies and addresses interpersonal relations, leadership behaviour, planning, leading, controlling, organising, administration and budgeting, HR business processes and mathematics. A five-point Likert (1932) rating scale, with ratings of 1 (strongly disagree), 2 (disagree), 3 (unsure), 4 (agree), and 5 (strongly agree) was used for the second and third parts of the questionnaire.

\section{Research procedure}

The questionnaire was distributed to 250 participants. Besides the $100 \%$ response rate of the original sample, 16 additional questionnaires were copied and completed. The researchers were unable to distinguish between the original and additional questionnaires. Consequently, the analysis was conducted on a total of 266 completed questionnaires.

\section{Data analysis}

Data was analysed by Statkon (University of Johannesburg statistical division), using the Statistical Package for the Social Sciences (SPSS version 21.0). Descriptive statistics were used to analyse data. The competencies were ranked based on the mean and standard deviation scores such that a higher central tendency indicated a stronger preference for the inclusion of such a competency. Competencies that received a rating of 4 and 5 were included and those that received a rating of 3 and below were excluded. The Cronbach's alpha test of reliability achieved scores over 0.90 for all variables measured with exception of the 'qualification' variable, which had a Cronbach's alpha score of 0.861 . This was due to the fact that some of the participants were uncomfortable with mathematics as a required competency for a technician position.

\section{Results}

Out of the 266 valid questionnaires analysed, the frequency responses received from the Eskom divisions are as follows: distribution division $40.2 \%$, transmission division $36.8 \%$, generation division $18.8 \%$ and corporate division $4.1 \%$. The departmental spread was recorded as follows: maintenance $37.9 \%$, engineering $28.4 \%$, operating $20.8 \%$, HR $3.8 \%$ and $9.1 \%$ did not indicate their department. The age profile of the participants ranged as follows: $45.9 \% 40-49$ years, $28.2 \%$ $30-39$ years, $16.9 \% 50-59$ years and $9 \% 29$ years and younger.

The gender profile of participants was predominately male at $68.9 \%$ with $31.1 \%$ female. The most prevalent of qualifications were National Diploma at $32.1 \%$ followed by National Certificates at $28.3 \%$. A postgraduate diploma was held by $19.2 \%$ of participants and $7.5 \%$ held a bachelor's degree. The most frequent range of experience in the technical field was 6-10 years (35.8\%), followed by $10-15$ years $(16.2 \%)$; range of experience at the supervisory level was 3-6 years $(30.1 \%)$ and $0-3$ years $(28.2 \%)$.

According to the findings, the following competencies are deemed to be significant for all supervisors, especially those that were promoted from the position of technician. The mean scores are provided for each competency with standard deviation scores in brackets: leadership 3.39 (0.636), planning 3.34 (0.578), leading 3.39 (0.586), controlling 3.31 (0.627), organising $3.32(0.639)$, administration $3.28(0.615)$, budgeting 3.07 (0.684), safety knowledge 3.37 (0.631), HR systems and processes 3.26 (0.642), training and development 3.19 (0.623) and qualification and experience 2.94 (0.650).

\section{Phase 2: Qualitative approach}

Qualitative research is aimed at understanding the meaning, experience and perception that people attach to their everyday lives (De Vos, 2002). Qualitative research is a non-statistical approach that elicits participants' accounts of meaning and experience (Creswell, 2009; Willis, 2007). According to Cooper and Schindler (2012), qualitative research attempts to understand how and why a phenomenon happened. For the purpose of this study, qualitative research using focus groups was conducted immediately after the quantitative survey results were analysed.

\section{Sample size}

The focus group participants were selected randomly from a total of 150 managers with a breakdown as follows: 60 supervisors, 60 line managers, 15 HR development (HRD) managers and $15 \mathrm{HR}$ managers. All managers were directly affected by the future transitioning of technicians into supervisory positions. To ensure that the groups were small enough to give everyone the opportunity to express an opinion and diverse enough to encourage participation, participants were split randomly into four groups of 50,50, 25 and 25. In each of the four focus groups, participants were further split into three or four groups to facilitate discussion, debate and agreement amongst 8 to 15 participants. Ideally, the focus groups should have been smaller to allow for rigorous discussion and debate; however, for the purpose of this study, the sample size fortunately allowed the groups to achieve the desired outcome.

\section{Research instrument}

The competencies that were identified in the quantitative phase were consolidated into two charts listing the key competencies of a technician's position and the key competencies of a supervisor's position. Participants of the focus groups were requested to agree with and accept each competency, then rank the degree of importance of each competency and recommend any further competency that 
may have been omitted. Finally, participants were requested to recommend the development or training interventions that would be essential to successfully transition an employee from the level of a technician to the level of a supervisor.

\section{Research procedure}

Participants in the focus group sessions were issued with the two charts generated from the quantitative survey findings listing the competencies of a technician and of a supervisor. Participants were also provided with flipcharts to record their discussion points. After discussions, participants were requested to agree, accept and validate each competency. Thereafter they had to prioritise and order each competency into those that were most important to those that were least important. A ranking scale of 1-5 was used, ranging from 'strongly disagree' to 'strongly agree'.

\section{Data analysis}

The data gathered from the focus group discussions were moderated to check if all groups had accomplished the tasks as requested. The charts were checked to identify if all stated competencies for both technician and supervisor were accepted. The degree of importance rankings were tallied to check if participants agreed on the priority assigned to each competency. Rankings of 4 ('agree') and 5 ('strongly agree') were interpreted as significant for the purpose of this phase of the study. The flipcharts were scanned for common additional competencies that groups included besides those stipulated on the charts provided as well as for the training intervention topics recommended for technicians transitioning into supervisory positions.

\section{Results}

The majority of the competencies that were listed on the technician and supervisory competencies charts obtained a degree of agreement score of between 4 and 5. Competencies of the supervisor were ranked as follows:

- Most important competencies (ranking of 5): interpersonal relations, leadership behaviour, organising ability, budgeting, safety knowledge, relevant qualification and experience.

- Less important competencies (ranking of 4): planning, leading, controlling, administration, training and development.

The focus group concluded that the competencies for the technician's position are aimed at improving the technical skills and knowledge, whilst the supervisory competencies are aimed at improving the management of individuals and teams and ensuring effective planning, organising, leading and controlling of the day-to-day operations.

In addition to the listed competencies of supervisors, the focus group participants added these competencies as highly necessary for junior management staff: conflict management, time management and managing meetings. For effective training and development interventions for technicians transitioning into supervisory positions, focus group participants recommended these skills be included: coaching, mentoring, talent management and networking skills.

\section{Discussion}

The competencies identified for the technician position and the supervisor position as per the literature review were accepted by participants in the quantitative survey and further validated by participants in the qualitative focus groups. The work of a technician involves the day-to-day operation and maintenance of various types of equipment (Barley \& Bechky, 1994). A technician is someone who has acquired specialised training and experience and who is skilled to utilise the technical instruments, techniques, equipment and procedures to solve technical problems (ECSA, 2003). Research participants agree that a technician uses a wide variety of systems, tools and equipment in analysing, scanning and investigating system networks and plant performance. Ideally, technicians should use their tools and equipment safely with minimal danger and damage to self, client and others.

A low rating of mathematics as a required competency for a technician indicates that many research participants are unsure of the importance of this competency for a technical position. Mathematics as a competency required for a supervisory position recorded a favourable frequency score of $62.9 \%$. The technical specification documents emphasised the importance of mathematics for a technician position, as technicians are expected to understand how to read drawings, calculate required amounts of specifications for the repairing of machines and maintain project schedules. This is supported by ECSA (2003), which states that the knowledge and understanding of mathematics for a technician's position provides technicians with a skill to perform fault-finding, designs and routine checks adequately.

Mathematics seems to be a contested requirement, which could be due to perceptions about its difficulty and the potential barriers to entry into a supervisory position for technicians who do not have high levels of mathematical proficiency. The organisation should launch an investigation into the current and required level of mathematical proficiency for a technician and thereafter promote mathematical skills via training interventions as well as policy documents.

Supervisors have more demands placed on them than technicians, as they have to ensure that they oversee the work of their teams. The survey results reveal a common acceptance of the definition of the role of the supervisor, especially the responsibility for team, departmental and organisational performance. The focus groups agreed that supervisors are expected to ensure that their team performance contributes to organisational success.

The findings of the survey confirm that supervisors have to create a balance between getting work done and building relationships within their teams. This is in support of Boone 
and Kurtz's (2011) argument that supervisors need to communicate clearly what is needed and establish a culture of customer-centricity, which has employee satisfaction at the centre of business performance. In addition, the results from the qualitative focus group sessions indicated that supervisors are expected to apply technical competencies, plan for the required resources for the execution of daily tasks, supervise their team and assess their team's performance.

Of the 11 supervisory competencies identified in this study, the leadership and leading competencies achieved the highest mean scores and were ranked as most important by focus group participants. Safety knowledge was highly significant with the second highest mean score and a focus group ranking of 5. Planning was the third placed competency identified as essential for supervisors, closely followed by interpersonal skills and organising ability. These findings reveal that the key competencies that are required for a supervisory position include planning, organising, directing, controlling and monitoring of daily activities of their teams.

These findings are in line with the literature where various authors have argued that there are four functions that are central to management or supervising of other employees: planning, organising, leading and controlling (De Beer \& Rossouw, 2005; Hilgert \& Leonard, 2008; Hood, 1990; Howard, 2003; Mintzberg, 2009; Rue \& Byars, 2004; Seethamraju \& Agrawal, 1999; Yulk, 2008). Four additional skills that are critical for a supervisor position are dealing with people, information-sharing, decision-making and problem-solving.

From the findings it is evident that transitioning from a technician to a supervisor involves recognising the required competencies essential for effectiveness at different performance levels (Charan et al., 2001). According to Aucoin (2002), for the technician to make the transition to a supervisor position, there are three critical skills required, namely technical, administrative and personnel or HR skills. Supervisors need to lead their teams and create a balance between getting the work done and building relationships. The focus groups agreed that leadership behaviour and interpersonal skills are critical for the supervisory position. Supervisors set a foundation for effective operations, workplace relationships and quality standards for all employees in the workplace.

The competency gaps between a technical position and a supervisory position were measured as a shift in competencies from a technical position to a supervisory position (Roberts \& Biddle, 1994). This shift is referred to as a transition. The literature trends reveal that when technicians make a transition into a management position, they often experience challenges, especially when managing teams (Hood, 1990). For example, the transition from an engineer (which is a technical field) to a manager is a difficult experience (Howard, 2003). The difficult experience of making the shift from technician to supervisor is a challenge that organisations can handle effectively through the implementation of necessary development and coaching interventions.

Organisations need to acknowledge that a transition should not be seen as a single process of just promoting a technician to a supervisory position and expecting that the same success that was achieved at the technician level will be achieved at a supervisory level. The transition should be viewed as a process (Hill, 2003; Hood, 1990; Newstrom, 2007). The transition process should be a swift and efficient process that is carefully executed to avoid slip-ups, unnecessary stress, low morale and substandard performance. Moreover, it is critical that the technicians who make a career transition to a supervisory position have the required skills and competencies to properly manage their team activities (Hood, 1990). Where there is a gap in the skills required to make the shift, organisations should implement necessary training interventions.

Training and development were confirmed in both the quantitative and qualitative phase as significant requirements for the transition from a technician to a supervisor. Training and development should aim to provide the necessary skills and competencies for the required position. The triangulation of the results of this study reveal that, as identified in the literature review, the survey and focus group participants agree that the competencies for technicians and supervisors differ and that technicians should be groomed to acquire and master the additional competencies required by supervisors.

\section{Implications of the findings}

The management competencies that are required to transition a technician to a supervisor have three important implications for the employees, managers and clients of the organisation. Firstly, the literature review may guide the organisation to identify the key competencies that are essential for a technician and a supervisor. The list of competencies for each position could be used as a tool for recruiting, engaging, retaining and addressing the gaps in the required key competencies for each position. Furthermore, the list of competencies could be an effective tool for transitioning a technician to a supervisory position.

Secondly, the findings reveal that the competencies for supervisors are shared by technicians; however, additional competencies are required in a supervisory position. More demands are placed on supervisors than on technicians (Hilgert \& Leonard, 2008; Hodgetts, 2007; Mintzberg, 2009). Supervisors need to create a balance between getting work done and building relationships within their teams (Badawy, 1995; Hilgert \& Leonard, 2008; Yulk, 2008). According to the focus group findings, supervisory positions are often complex: in addition to allocating and supervising the work of individuals and teams, there is the added responsibility of managing conflict amongst team members, managing time spent by teams on tasks and attending and managing meetings, which could sometimes last an entire workday. 
Thirdly, the findings of this study confirm that organisations should implement development or training interventions that are essential to successfully transition an employee from the level of a technician to the level of a supervisor. The results reveal that such a transition should not be treated as a one-off event, but as a process that takes time; hence, it should be seen as progressing through five overlapping stages that occur over several months or even years (Badawy, 1995; Newstrom, 2007). Therefore, organisations need to build effective training and development interventions and design supporting structures to ensure the smooth transition of technicians into supervisory positions.

The proposed development solutions or interventions to enhance management competencies that are required in the transition from a technician to a supervisory position may be used to guide HRD professionals in supporting the development of a learning environment in which there is sharing of knowledge and skills. Organisations should implement processes to identify and support the potential challenges that are faced by the technicians who make the transition into supervisory positions.

\section{Limitations of the study}

The study was conducted in one organisation within the energy sector; hence, generalisation of the results into other organisations is limited.

The competencies used in the questionnaires could not always be substantiated by the literature as there was a scarcity of literature on the competencies required for a technician and a supervisor, especially those within an electricity generation organisation. However, the competencies identified in this study will fulfil the purpose for which it was intended, especially for the organisation under study. It is hoped that this study will form a theoretical framework for further studies on the subject of supervisory and management competencies as required by junior staff seeking promotion opportunities.

\section{Recommendations for future research}

As a recommendation, further research should be conducted on a variety of organisations in the energy sector to verify the competencies described in this paper as well as to allow for generalisation of the results.

Further research is required for a broader population including different types of industries that employ technicians and supervisors. A future study could investigate the more complex designs involving inferential statistics to determine which competencies have the highest prediction value on the effective execution of work when a technician is promoted to a supervisory position.

\section{Conclusion}

The main objective of this study was to establish the management competencies that are required for a technician to make the transition into a supervisory position. This study also provided a comprehensive view on the management competencies that are required for a technician to make a smooth transition to a supervisory position. The response rate and the interest in the content of this research confirm the importance of this subject within the studied organisation.

To achieve these in-depth research findings, this study applied a sequential mixed methods research approach. The quantitative phase utilised the survey questionnaire to identify and verify the competencies identified during the literature review. The results from the quantitative phase were used as input to the qualitative phase of this study. The qualitative phase utilised focus group discussions to validate the identified competencies, assign a degree of importance and identify additional competencies for technicians transitioning into supervisors.

Research participants recommended that training or development interventions are imperative to successfully transition employees from a technician to a supervisory position. The overall findings confirm that when technicians are promoted to a supervisory position, the additional competencies for supervisors are not considered and technicians are not provided with the essential training that is critical for the supervisory position.

\section{Acknowledgements Competing interests}

The authors declare that they have no financial or personal relationships that may have inappropriately influenced them in writing this article.

\section{Authors' contributions}

S.R.M. (University of Johannesburg) performed the research and wrote the article. C.G. (University of Johannesburg) was a supervisor.

\section{References}

Analyzer Technician Opportunities Project. (2009). Analyzer Technician Competency Model. Baytown, TX: National Science Foundation, Lee College.

Aucoin, B. (2002). From engineer to manager: Mastering the transition. Norwood, MA: Artech House.

Badawy, M. (1995). Developing managerial skills in engineers and scientists: Succeeding as a technical manager. (2nd edn.). New York, NY: John Wiley \& Sons.

Barley, S. (1996). Technicians in the workplace: Ethnographic evidence for bringing work into organizational studies. Administrative Science Quarterly, 41, 404-441. $\mathrm{http}: / /$ dx.doi.org/10.2307/2393937

Barley, S.R., \& Bechky, B. (1994). In the backrooms of science: The work of technicians in science labs. Work and Occupations, 21, 85-126. http://dx.doi. org/10.1177/0730888494021001004

Becker, M. (2009). Competence matrix for the sector electronics/electrical engineering. Paper presented at the Vocational Qualification Transfer System (VQTSII), Flensburg, Germany, June.

Bernadi, L., Kleim, S., \& Von der Lippe, H. (2007). Social influences on fertility: A comparative mixed methods study in Eastern and Western Germany. Journal of MixedMethods Research,1,23-47. http://dx.doi.org/10.1177/2345678906292238

Boone, L.E., \& Kurtz, D.L. (2011). Contemporary Business. (14th edn.). New York, NY: John Wiley \& Sons, Inc.

Charan, R., Drotter, S., \& Noel, J. (2001). The leadership pipeline. San Francisco, CA: Jossey-Bass.

Cooper, D.R., \& Schindler, P.S. (2012). Business research methods. (9th edn.). New York, NY: McGraw-Hill. 
Creswell, J.W. (2009). Qualitative, quantitative and mixed methods approaches. (3rd edn.). Thousand Oaks, CA: Sage Publications, Inc.

Creswell, J.W., \& Plano, C. (2011). Designing and conducting mixed methods research. Thousand Oaks, CA: Sage Publications, Inc.

De Beer, A., \& Rossouw, D. (2005). Focus on operational management. A generic approach. Cape Town, South Africa: Juta.

De Vos, A.S. (2002). Research at grassroots for the social science and the helping profession. Pretoria, South Africa: Van Schaik.

Ebberwein, C.A., Krieshok, T.S., Ulven, J.C., \& Prosser, E.C. (2004). Voices in transition Lessons on career adaptability. Career Development Quarterly, 52(4), 292-308. $\mathrm{http}: / / \mathrm{dx}$.doi.org/10.1002/j.2161-0045.2004.tb00947.x

Engineering Council of South Africa (ECSA). (2003). ECSA policy statement R2/1C. Acceptable engineering work for registration of professional engineering technicians. Johannesburg, South Africa: ECSA.

Freedman, A. (1998). Pathways and crossroads to institutional leadership. Consulting Psychology Journal, 50, 131-151. http://dx.doi.org/10.1037/1061-4087.50.3.131

Gratton, L. (2000). Living strategy: Putting people at the heart of corporate purpose. London, UK: Pearson Education Limited.

Greer, C.R., \& Plunkett, W.R. (2000). Supervision. Diversity and teams in the workplace. (9th edn.). Upper Saddle River, NJ: Prentice Hall.

Hall, D.T. (2002). Careers in and out of organizations. Thousand Oaks, CA: Sage.

Handschin, B. (2007). Mastering the transition from technician to technical manager. Talent Management Consulting. Retrieved June 02, 2012, from http://www. talentmci.com

Hilgert, R.L., \& Leonard, E.C. (2008). Supervision: Concepts and practice of management. (9th edn.). Cincinnati, $\mathrm{OH}$ : South Western.

Hill, L. (2005). Becoming a manager. Boston, MA: Harvard Business School Press.

Hodgetts, R.M. (2007). Effective supervision: A practical approach. New York, NY: McGraw-Hill.

Hood, D. (1990). Transition engineer to manager: Specialist to generalist. Presented at IEEE International Engineering Conference, Management Through the Year 2000 Gaining the Competitive Advantage, Howthorne, CA, 21-24 October 1990.

Howard, C. (2003). From engineer to engineering manager: A qualitative study of the experiences, challenges, and individual transitions for engineering managers in aerospace industries. Retrieved May 26, 2012, from https://etda.libraries.psu. edu/paper/6057/1409

Ito, J.K., \& Brotheridge, C.M. (2005). Does supporting employees' career adaptability lead to commitment, turnover, or both. Human Resources Management, 44, 5-19. http://dx.doi.org/10.1002/hrm.20037

Jogulu, U.D., \& Pansiri, J. (2011). Mixed methods: A research design for management doctoral dissertations. Management Research Review, 34(6), 687-701. http:// dx.doi.org/10.1108/01409171111136211

Kadushin, A., \& Harkness, D. (2002). Supervision in social work. (4th edn.). USA Columbia University Press.

Katz, R. (2003). The human side of managing technological innovation. (2nd edn.). New York, NY: Oxford University Press.

Lewis, J.P. (2009). Making the transition from engineer or technical expert to manager. Business Management, 10, 21.
Likert, R. (1932). A technique for the measurement of attitudes. Archives of Psychology, 140, 1-55.

Louis, M. (1980). Career transition: Varieties and commonalities. Academy of Management Review, 5(3), 325-340. http://dx.doi.org/10.2307/257108

Mahapatro, B.B. (2010). Human resource development. In B.B. Mahapatro (ed.), Human resource management (pp. 272-298), New Delhi, India: New Age International.

Mintzberg, H. (2009). The structuring of organisations. Englewood Cliffs, NJ: PrenticeHall.

National Academy of Engineering. (2005). The engineer of 2020: Vision of engineering in the new century. Washington, DC: National Academies Press.

Newstrom, J.W. (2007). Supervision: Managing for results. (9th edn.). New York, NY: McGraw-Hill.

Osipow, S., \& Fitzgerald, L. (1996). Theories of career development. (4th edn.). Toronto, Canada: Allyn \& Bacon.

Reio, T.G., \& Sutton, F.C. (2006). Employer assessment of work-related competencies and workplace adaptation. Human Resource Development Quarterly, 17(3) 305-324. http://dx.doi.org/10.1002/hrdq.1176

Roberts, K., \& Biddle, J. (1994). The transition into management by scientist and engineers: A misallocation of efficient use of human resources. Human Resource Management, 33(4), 561-579. http://dx.doi.org/10.1002/hrm 3930330406

Rubin, A., \& Babbie, E. (2005). Research methods for social work. (5th edn.). Belmont, CA: Thomson, Brooks, Cole.

Rue, L.W., \& Byars, L.L. (2004). Supervision: Key link to productivity. Boston, MA: McGraw-Hill, Irwin.

Seethamraju, R., \& Agrawal, R. (1999). Engineers as managers: A conceptual model of transition. Presented at the Management of Engineering and Technology Portland International Conference (PICMET), Portland, OR, 25-29 July 1999. http://dx.doi. org/10.1109/PICMET.1999.787818

Technician Council. (2011). Presentation - The Technician Council. London, UK: The Technician Council.

Teddlie, C., \& Tashakkori, A. (2009). Foundations of mixed methods research: Integrating quantitative and qualitative techniques in the social behavioural sciences. London, UK: SAGE.

Thamhain, H. (1991). From engineer to manager. Training \& Development, 45(9), 66-70.

United States Office of Performance Management. (1999). Workplace compensations and performance services. Engineering Technician Series GS-0802. Washington, and performan

Willis, J. (2007). Foundations of qualitative research. Thousand Oaks, CA: Sage Publication.

Woodruffe, C. (2003). What is meant by a competency? Leadership and Organisational Journal, 14(1), 26-36.

Yulk, G. (2008). Leadership in organisations. (7th edn.). Albany, NY: University of Albany.

Zikmund, W.J., Babin, B.J., Carr, J.C., \& Griffin, M. (2013). Business Research Methods (9th edn.). Boulevard, MA: Cengage Learning. 